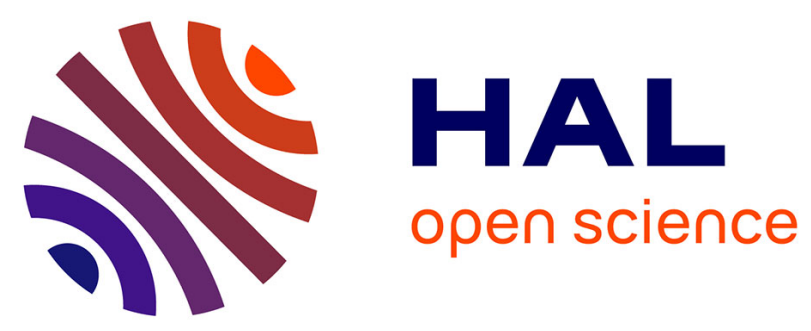

\title{
Elastic properties and surface damage resistance of nitrogen-rich (Ca,Sr)-Si-O-N glasses
}

Pathikumar Sellappan, Ali Sharafat, Vincent Keryvin, Patrick Houizot, Tanguy Rouxel, Jekabs Grins, Saeid Esmaeilzadeh

\section{To cite this version:}

Pathikumar Sellappan, Ali Sharafat, Vincent Keryvin, Patrick Houizot, Tanguy Rouxel, et al.. Elastic properties and surface damage resistance of nitrogen-rich (Ca,Sr)-Si-O-N glasses. Journal of NonCrystalline Solids, 2010, 356 (41-42), pp.2120-2126. 10.1016/j.jnoncrysol.2010.07.043 . hal-00830343

\section{HAL Id: hal-00830343 \\ https://hal.science/hal-00830343}

Submitted on 11 Apr 2014

HAL is a multi-disciplinary open access archive for the deposit and dissemination of scientific research documents, whether they are published or not. The documents may come from teaching and research institutions in France or abroad, or from public or private research centers.
L'archive ouverte pluridisciplinaire HAL, est destinée au dépôt et à la diffusion de documents scientifiques de niveau recherche, publiés ou non, émanant des établissements d'enseignement et de recherche français ou étrangers, des laboratoires publics ou privés. 


\title{
Elastic properties and surface damage resistance of nitrogen-rich (Ca,Sr)-Si- O-N glasses
}

\author{
Pathikumar Sellappan ${ }^{a}$, Ali Sharafat ${ }^{b}$, Vincent Keryvin $^{a, c}$, Patrick Houizot $^{a}$, Tanguy Rouxel $^{a}$, \\ Jekabs Grins ${ }^{b}$ and Saeid Esmaeilzadeh ${ }^{b}$
}

a LARMAUR, ERL CNRS 6274, Université de Rennes 1, Campus de Beaulieu, 35042 Rennes cedex, France.

${ }^{\mathrm{b}}$ Department of Physical, Inorganic and Structural Chemistry, Arrhenius Laboratory, Stockholm University, SE-106 91 Stockholm, Sweden.

${ }^{\mathrm{c}}$ LiMATB, EA 4250, Université de Bretagne Sud, BP 92116, 56321Lorient cedex, France.

* Corresponding Author:

Pathikumar Sellappan

Research Scholar

Tel: +33223235323

Fax: +33223236111

E-mail: pathikumar.sellapan@univ-rennes1.fr 


\begin{abstract}
$\mathrm{Ca}$ and $\mathrm{Sr}$ based oxynitride glasses with very high nitrogen content have been synthesized using metal hydrides as primary precursors. Values of Young's modulus, shear modulus, bulk modulus and Poisson's ratio were determined by means of ultrasonic echography. Vickers microindentation has been used to characterize hardness and indentation fracture toughness behaviour. Elastic moduli were found to increase linearly with nitrogen content, with a highest value of Young's modulus of $135 \mathrm{GPa}$, for a Ca-glass with 58 e/o of nitrogen. The Sr-glasses exhibit lower elastic moduli than Ca glasses. Poisson's ratio, hardness, indentation fracture toughness, crack initiation load and surface damage resistance were found to increase with increasing nitrogen content for both glass series.
\end{abstract}

Keywords: oxynitride glass; elastic modulus; Poisson's ratio; hardness; brittleness; fracture toughness; high nitrogen content. 


\section{Introduction}

The addition of nitrogen to silicate glasses significantly affects the physical properties. For instance with increasing nitrogen content, glass transition temperature $\left(T_{g}\right)$ [1-3], viscosity ( $)[1]$, hardness $\left(\mathrm{H}_{\mathrm{v}}\right)[2,4,6-8]$, Young's modulus $(\mathrm{E})[2,6,9,10]$, and refractive index (n) $[1$, $4,7,8]$ increases, while the thermal expansion coefficient $(\alpha)$ [11] decreases. The increase of elastic moduli was reported for various chemical systems including Y-Al-Si-O-N [6, 9, 10], NaB-Si-O-N [12], Na-Ca-Si-O-N [12], Mg-Si-Al-O-N [13], Ca-Si-O-N [14], Ca-Si-Al-O-N [2, 16] and Ca-Si-Al-O-N-F [15] glasses. The elastic moduli were also found to increase with the field strength of the modifying cations $(\mathrm{Mg}, \mathrm{Ca}, \mathrm{Y})$.

Oxynitride glasses are mostly obtained by conventional melting of mixtures of glass modifier metal oxides, $\mathrm{SiO}_{2}$ and $\mathrm{Si}_{3} \mathrm{~N}_{4}$. Recent studies have shown that $\mathrm{La}-\mathrm{Si}-\mathrm{O}-\mathrm{N}$ [5], Ca-Si-ON [3] and Sr-Si-O-N [4] glasses can be formed over wider compositional ranges, by using the electropositive elements in their metallic state or as metal hydrides as starting materials. The latter route was used in the present study and it allows to reach levels of nitrogen content higher than those obtained by standard melting. These glasses retain high amounts of the electropositive elements and nitrogen and exhibit very high values of glass transition temperature, microhardness and refractive index $[3,7]$.

Elastic properties and the surface damage resistance are of particular interest for this newly synthesized nitrogen rich oxynitride glass series. Several authors have attempted to use the indentation radial cracking pattern to estimate fracture toughness on brittle solids (Indentation fracture toughness, IFT) [27, 28]. In this article we report the intimate relationship between elastic properties of the high nitrogen rich oxynitride samples, in particular Poisson's ratio, and its relation to the indentation behaviour. The present study was undertaken to establish the dependence of Young's modulus, shear modulus, Poisson's ratio, hardness, indentation brittleness and indentation fracture toughness on the nitrogen content for alkaline earth (AE) systems like $\mathrm{Ca}-\mathrm{Si}-\mathrm{O}-\mathrm{N}$ and $\mathrm{Sr}-\mathrm{Si}-\mathrm{O}-\mathrm{N}$ glasses. The indentation cracking behaviour for the above mentioned glass series is analyzed in detail and compared with its Poisson's ratio and nitrogen content.

\section{Experimental}

Starting compositions were prepared by mixing appropriate amounts of $\mathrm{CaH}_{2},(98 \%$ with $\mathrm{Mg}<1 \%$, Alfa Aesar GmbH \& Co), Sr metal (99.9\% in mineral oil, ABCR GmbH \& Co), $\mathrm{Si}_{3} \mathrm{~N}_{4}$ 
(UBE, SN-E10), and $\mathrm{SiO}_{2}(99.9 \%, \mathrm{ABCR} \mathrm{GmbH} \& \mathrm{Co})$ powders. Six gram batches of each composition were grinded within a glove box in argon atmosphere, in order to protect the mixture from oxidation. The mixtures were melted in $\mathrm{Nb}$ crucibles at $1500-1750^{\circ} \mathrm{C}$ using a radio frequency furnace. Due to element losses during the synthesis, all glass compositions were determined by energy dispersive X-ray micro-analysis for cations and combustion analysis for anions. Details concerning synthesis and additional characterisations are given in references 3 and 4 .

\subsection{Density, molar volume, $n_{B O}$ and compactness}

The densities of the glasses were measured according to the Archimedes principle (ASTM C373-88) in distilled water. Density values were calculated using the expression $\rho=m_{d} /\left(m_{d^{-}}\right.$ $\left.m_{w}\right) \cdot \rho_{\text {water, }}$ where $m_{d}$ is the weight of the dry sample, $m_{w}$ is the weight of the immersed sample and $\rho_{\text {water }}$ at $20^{\circ} \mathrm{C}$ is $0.9982 \mathrm{~g} / \mathrm{cm}^{3}$. Sample weights were between 200 and $400 \mathrm{mg}$ and measured glass densities were reproducible to $\pm 0.01 \mathrm{~g} / \mathrm{cm}^{3}$.

Molar volumes (MV) of the glasses were calculated using the following expression (1), with $X_{i}$ and $M_{i}$ being respectively the mole fraction and molar mass of element $i$ respectively and $\rho$ is the density of the glass.

$$
\mathrm{MV}=\sum_{\mathrm{i}} \mathrm{X}_{\mathrm{i}} \mathrm{M}_{\mathrm{i}} / \rho
$$

The compactness $\left(\mathrm{C}_{\mathrm{g}}\right)$ of the glasses, which is related to the excess volume of the glass, is defined as the ratio between the summed volume of the individual ions and the corresponding volume of glass. It is calculated using the expression

$$
\mathrm{C}_{\mathrm{g}}=\sum_{\mathrm{i}} \mathrm{X}_{\mathrm{i}} \mathrm{V}_{\mathrm{i}} \mathrm{N} / \mathrm{MV}
$$

where $\mathrm{V}_{\mathrm{i}}$ is the ion volume for $\mathrm{i}^{\text {th }}$ element, calculated using the ionic radii given by Shannon [17], and $N$ is Avogadro's number.

For oxide glasses, the number of bridging oxygen atoms per glass-forming cation, $\mathrm{n}_{\mathrm{BO}}$, provides a measurement of the network cross-link degree. This number is defined as

$$
\mathrm{n}_{\mathrm{BO}}=4-\sum_{\mathrm{i}} \mathrm{M}_{\mathrm{i}} \mathrm{Z}_{\mathrm{i}} /\left(\sum_{\mathrm{j}} \mathrm{F}_{\mathrm{j}}\right)
$$

where $M_{i}$ and $z_{i}$ are the atomic fraction (after deduction of the number of charge compensators) and the valency of the $i^{\text {th }}$ modifying cation and $F_{j}$ is the fraction of the $j^{\text {th }}$ glass- 
forming cation. In rough approximation, assuming that all nitrogen atoms are 3 -fold coordinated to silicon atom, the $\mathrm{n}_{\mathrm{BO}}$ number of oxynitride glasses can be estimated by replacing $\{\mathrm{O}\}$ by an equivalent anionic concentration $\left\{\mathrm{O}^{*}\right\}$, with $\left\{\mathrm{O}^{*}\right\}=(\{\mathrm{O}\}+3 / 2\{\mathrm{~N}\})[18]$.

\subsection{Elastic moduli}

The elastic moduli were calculated by means of ultrasonic echography (USE) with 10 $\mathrm{MHz}$ piezoelectric transducers. The travel time for wave round trips of multiple echoes of the

primary signal was measured by a digital oscilloscope and computed using Hilbert transform with an accuracy of $\pm 2 \mathrm{~ns}$. The specimen thickness was determined using a digital micrometer with an accuracy of $\pm 1 \mu \mathrm{m}$. The ultrasonic velocities of longitudinal $\left(\mathrm{V}_{\mathrm{L}}\right)$ and transverse $\left(\mathrm{V}_{\mathrm{T}}\right)$ waves were calculated from the thickness and transit time values. The time separating two successive echoes $\tau$ is related to the propagation velocity $\mathrm{V}$ by $\tau=2 \mathrm{~L} / \mathrm{V}$ where $\mathrm{L}$ is the thickness of sample. The following classical relationships were used to estimate Young's (E), shear (G) and bulk moduli (K) as well as Poisson's ratio (v):

$$
\begin{aligned}
& \mathrm{E}=\rho \frac{\left(3 \mathrm{~V}_{\mathrm{L}}^{2}-4 \mathrm{~V}_{\mathrm{T}}^{2}\right)}{\left(\mathrm{V}_{\mathrm{L}} / \mathrm{V}_{\mathrm{T}}\right)^{2}-1} \\
& \mathrm{G}=\rho \mathrm{V}_{\mathrm{T}}^{2} \\
& \mathrm{~K}=\frac{\mathrm{E}}{3(1-2 v)} \\
& v=\frac{\mathrm{E}}{2 \mathrm{G}}-1
\end{aligned}
$$

\subsection{Indentation}

The indentation behaviour (micro-hardness and reduced elastic modulus) was investigated using an instrumented indentation apparatus (Fischerscope H100C, Germany) with a diamond Vickers indenter. All the measurements were performed in a thermally regulated room, at $20{ }^{\circ} \mathrm{C}$ in air on mirror-polished surfaces (diamond suspensions up to $1 \mu \mathrm{m}$ particle size). Loads between $30 \mathrm{mN}$ and $1000 \mathrm{mN}$ were applied at constant loading rate. The dwell time at maximum load was $5 \mathrm{~s}$. All the characteristics were averaged over measurements on 10 indentations per grade. The hardness values obtained directly from the measurement $\left(\mathrm{H}_{\mathrm{IT}}\right)$ and the indentation - derived elastic modulus, $\mathrm{E}_{\mathrm{IT}}$, were determined by using the unloading part of the indentation curve [25]. The estimation of $\mathrm{E}_{\mathrm{IT}}$ from indentation experiments can be done in the following way. 


$$
\begin{aligned}
& \mathrm{E}_{\mathrm{IT}}=\mathrm{E}_{\mathrm{r}}\left(1-v^{2}\right) \\
& \mathrm{E}_{\mathrm{r}}=\frac{\mathrm{S} \sqrt{\Pi} \sqrt{\mathrm{A}}}{2}
\end{aligned}
$$

where, $E_{r}$ is the reduced Young's modulus, which was directly obtained from the measurement following Oliver \& Pharr method [25], S is the experimentally measured contact stiffness of the upper portion of the unloading data, A is the projected contact area and $v$ is Poisson's ratio value measured by the ultrasonic echography. The indentation elastic modulus $\left(\mathrm{E}_{\mathrm{IT}}\right)$ results were compared with the ultrasonic echography measurement in Table 2.

Vickers $\left(\mathrm{H}_{\mathrm{V}}\right)$ and Meyer's macro-hardness $(\mathrm{H})$ were measured using a Matsuzawa hardness tester (Model VMT-7s, Japan) with a pyramid shaped diamond indenter. A load of 500 $\mathrm{g}(4.903 \mathrm{~N})$ was applied on the polished glass sample surface. At least 5 indentations were made on each sample, using the average indentation diagonal length to calculate hardness values in $\mathrm{GPa}$. The indentation diagonal lengths were measured using an optical microscope and Meyer's hardness and Vickers hardness values calculated using the following expression

$$
\begin{aligned}
& \mathrm{H}=\frac{\mathrm{P}}{2 \mathrm{a}^{2}} \\
& \mathrm{H}_{\mathrm{V}}=1.842 \frac{\mathrm{P}}{\mathrm{d}^{2}}
\end{aligned}
$$

with $\mathrm{P}$ (in Newton) the load applied on the indenter, $\mathrm{d}$ (in meter), the average indentation diagonal length and a (in meter) is diagonal half length.

\subsubsection{Indentation fracture toughness and indentation brittleness}

Indentation fracture toughness $\left(\mathrm{K}_{\mathrm{c}}\right)$ values were calculated based on the corner cracks generated during indentation. Usually, when the ratio $\mathrm{c} / \mathrm{a}$ is greater than 2.5 , the visible cracks are half-penny median-radial cracks while for c/a less than 2.5, Palmquist radial cracks are seen on the surface ( $c$ is the corner crack length 1 plus the diagonal half length a). For the first case, $(\mathrm{c} / \mathrm{a}>2.5)[27]$,

$$
\mathrm{K}_{\mathrm{C}}=\alpha\left(\frac{\mathrm{E}}{\mathrm{H}}\right)^{1 / 2} \frac{\mathrm{P}}{\mathrm{C}^{3 / 2}} \quad \text { for } \mathrm{c} / \mathrm{a}>2.5
$$

where $\alpha$ depends on the indenter geometry and Poisson's ratio of the material as,

$$
\alpha=\frac{0.0352}{1-v}(\cot \psi)^{2 / 3}
$$


where $\psi$ is conical apex angle of the Vickers pyramid, that is $70.3^{\circ}$. It gives $\alpha$ of 0.019 . If the cracking systems follow the second case, $(\mathrm{c} / \mathrm{a}<2.5)$ [28],

$$
\mathrm{K}_{\mathrm{C}}=0.035 \frac{\mathrm{H}_{\mathrm{V}} \sqrt{\mathrm{a}}}{\phi}\left(\frac{\mathrm{E} \phi}{\mathrm{H}_{\mathrm{V}}}\right)^{2 / 5}\left(\frac{1}{\mathrm{a}}\right)^{-1 / 2} \quad \text { for } \mathrm{c} / \mathrm{a}<2.5
$$

where 1 is the corner crack length and $\Phi$ is the constraint factor while using Vickers hardness instead of Meyer's hardness; It is $\approx 3$.

Crack initiation phenomenon in glassy systems can be linked to the brittleness of glass through Lawn and co-worker's method [27, 30-31]. The cracking indentation threshold in terms of critical load $\mathrm{P}_{\mathrm{c}}$ and residual Vickers half diagonal dimension $\mathrm{a}_{\mathrm{c}}$ can be obtained via an index of brittleness defined as the ratio of hardness-to-toughness $\mathrm{H} / \mathrm{K}_{\mathrm{c}}$. The critical numbers for crack initiation are then given by:

$$
\begin{aligned}
& \mathrm{P}_{\mathrm{C}}=\lambda_{0} \mathrm{~K}_{\mathrm{C}}\left(\frac{\mathrm{K}_{\mathrm{C}}}{\mathrm{H}}\right)^{3} \\
& \mathrm{a}_{\mathrm{C}}=\mu_{0}\left(\frac{\mathrm{K}_{\mathrm{C}}}{\mathrm{H}}\right)^{2}
\end{aligned}
$$

where $\lambda_{0}$ and $\mu_{0}$ are geometrical constants. Taking a large number of ceramics, Lawn and Marshall found $\lambda_{0}=16000$ (for ideal half-penny crack and ignoring effects due to contact friction, residual stress, etc) or $\lambda_{0}=22000$ (for approximate calculation based on ideal penny median crack nuclei) and $\mu_{0}=120$ [31]. Changing $\lambda_{0}$ from 16000 to 22000 does not change the crack initiation values much compared to the experimentally observed values.

\section{Results}

\subsection{Density, molar volume, $n_{B O}$ and compactness}

Experimental results obtained on $\mathrm{Ca}$ and $\mathrm{Sr}$ glasses are summarized in Table 1. For the $\mathrm{Ca}$

glasses, the density varies between 3.02 and $3.24 \mathrm{~g} / \mathrm{cm}^{3}$, the molar volume between 7.37 and 7.96 $\mathrm{cm}^{3} /$ mole and the compactness between 0.57 and 0.62 . The density increases with increasing nitrogen content and the molar volume decreases, in agreement with previously reported data on the same glass system [3]. For the Sr glasses, the present data, together with data given in reference 4 for a larger set of compositions, shows that the density also increases with $\mathrm{N}$ content, however; the density has a larger dependence on the $\mathrm{Sr}$ content, increasing with increasing $\mathrm{Sr}$ 
content. The molar volume decreases with nitrogen content, while a dependence on $\mathrm{Sr}$ content is not statistically significant.

Calculated values of the number of bridging oxygen atoms per glass-forming cation $\left(\mathrm{n}_{\mathrm{BO}}\right)$ for $\mathrm{Ca}$ and $\mathrm{Sr}$ glasses are given in Table 1. For Ca glasses the values varies between 3.22 to 3.34 and for Sr glasses between 3.22 to 3.47. Dependencies on the modifying cation effect can not be derived from this data but with increasing nitrogen content, the $\mathrm{n}_{\mathrm{BO}}$ decreases.

\subsection{Elastic moduli}

Elastic property values of the oxynitride samples are given in Table 1 along with other measured physical properties. Young's modulus and shear modulus for the $\mathrm{Ca}$ and $\mathrm{Sr}$ glasses are plotted in Fig. 1 and Fig. 2, as a function of nitrogen content. The moduli depend on the strength of bonds, both in the $\mathrm{Si}(\mathrm{O}, \mathrm{N})_{4}$ tetrahedra of the glass network and between modifiers $(\mathrm{Ca}$ or $\mathrm{Sr})$ and the anions $(\mathrm{O}, \mathrm{N})$, reflecting the packing state of the atoms. The bond strength between the modifiers and $\mathrm{O}$ or $\mathrm{N}$ is weaker than that of bonds between the anions and $\mathrm{Si}$ [9]. Both moduli increase substantially with the nitrogen content. The highest values 121 and $47.8 \mathrm{GPa}$, of E and $\mathrm{G}$, respectively were observed for the glass with 40 e/o $\mathrm{N}$ using the USE technique. Two samples (id 5 \&7) could not be characterized using USE technique, because of their small geometrical dimensions. For those two samples Poisson's ratio values were estimated based on the $\mathrm{n}_{\mathrm{BO}}$ using Fig. 3 and $E$ values were computed using Eq. 8, since $E_{\mathrm{r}}$ values has been directly measured using micro-indentation experiments [25]. In the given series of oxynitride samples values of $\mathrm{E}$ and $\mathrm{G}$, 135 and $52.8 \mathrm{GPa}$, were observed for the composition with 58 e/o N. Fig. 1 clearly indicates that increasing the nitrogen content leads to increase the elastic modulus. The shear modulus $(G)$ values (for id 5\&7) has been obtained using the following expression,

$$
\mathrm{G}=\frac{\mathrm{E}}{2(1+v)}
$$

E varies between 82.8 and 104.1 GPa for Sr based glass series. Estimating E and G as explained above by using micro-indentation technique has been repeated for the entire series. The results were compared with the values measured by means of USE technique, Fig. 1 \& Fig. 2. Two Sr glasses with nitrogen contents around 38 e/o show lower values, than the Ca glasses with similar $\mathrm{N}$ contents. This is presumably due to smaller cationic field strength of $\mathrm{Sr}$ than $\mathrm{Ca}$. The bulk modulus $(\mathrm{K})$ measures the resistance to elastic shrinkage under hydrostatic compression. It 
is defined as the pressure increase needed to cause a given relative decrease in volume. Consistently, high $\mathrm{C}_{\mathrm{g}}(0.618)$ glasses have high bulk modulus (102.3 GPa) values, Fig. 4.

\subsection{Poisson's ratio}

Poisson's ratio is defined as the ratio of transverse contraction strain to longitudinal extension strain in the direction of elastic loading in pure tension and is a measure of the resistance of a material to volume change upon change of shape. It is small for shear-resistant materials, such as covalently bonded solids, and tends towards 0.5 for incompressible bodies. For glasses in general, $v$ has values between 0.1 and 0.4 and decreases with increasing polymerisation degree of glass network [18]. High cross-link atomic network results in low atomic packing density and it results open structures like silica and germania. Silicate glasses have typically $v$ values around $0.2-0.25$, while oxynitride silicate glasses exhibit higher values, up to $0.36[19,20]$. Metallic glasses generally exhibit Poisson's ratio above 0.3 [26].

For the given glass series, Poisson's ratio varies between 0.262 and 0.308 . Eventhough an increase in $v$ with nitrogen content is obtained for the Sr-glass series, the situation is less clear for the Ca-glass series. Poisson's ratio values plotted against $\mathrm{n}_{\mathrm{BO}}$ values in Fig. 3 shows the expected trends like the other oxide systems [18].

The fracture on brittle solids usually occurs due to the generation and growth of a flaw on the surface rather than in the bulk. Knowing the mechanical behavior of surfaces plays an important role in controlling the strength of glass. Since brittle fracture in glass mostly initiates from pre-existing flaws at the surface, sharp contact loading experiments are suitable to study both the flaw formation and the crack initiation process. The resistance of glass to crack initiation can be obtained through micro-indentation studies under low loads. Instrumented indentation observation using optical microscopy on glass samples reveals that the samples which are having high Poisson's ratio in each glass series need higher load to initiate cracks than the samples with low Poisson's ratio. Onset of cracking during indentation for the loads between $300-1000 \mathrm{mN}$, was observed around the indentation. Sr-based glass series cracks at much lower load than the $\mathrm{Ca}$ based glass samples, as shown in Fig. 5. It shows that as the atomic cross-linking degree decreases, the atomic packing increases and at the same time local shear is made easier.

\subsection{Instrumented indentation}


The indentation hardness $\left(\mathrm{H}_{\mathrm{IT}}\right)$, Vickers hardness $\left(\mathrm{H}_{\mathrm{V}}\right)$ and the indentation derived reduced elastic modulus $\left(\mathrm{E}_{\mathrm{r}}-\mathrm{IT}\right)$ of AE-Si-O-N glasses, are given as a function of the composition along with the reduced modulus calculated using the measured elastic properties $\left(\mathrm{E}_{\mathrm{r}}-\mathrm{USE}\right)$ in Table 2. The instrumented indentation hardness $\left(\mathrm{H}_{\mathrm{IT}}\right)$ for $100 \mathrm{mN}$ obtained by using the unloading part of the indentation curve [25]. The indentation behavior of the oxynitride samples was compared with the silica and float glass (or window glass). Dependencies on the alkaline earth content or nitrogen cannot be reliably established for the measured hardness values. In general, the hardness values are found to increase with increase in the nitrogen content. The $\mathrm{Ca}$ based glasses have higher hardness values than the $\mathrm{Sr}$ based series. The instrumented elastic modulus $\left(\mathrm{E}_{\mathrm{IT}}\right)$ values for the given series are close to Young's modulus (E) values measured by the ultrasonic echography method and the difference between both the values varies between 5 to $10 \%$, Table 2 .

\subsubsection{Indentation toughness and brittleness}

Indentation fracture toughness has been evaluated for a $4.903 \mathrm{~N}(500 \mathrm{~g})$ indentation load for which the cracking systems on the polished surface are visible (four corner cracks). For this load, the ratio c/a was always greater than 2.5. Indentation fracture toughness $\left(\mathrm{K}_{\mathrm{c}}\right)$ values using Eq. (12) are reported in Table. 3 along with Meyer's hardness $(H)$, Vickers hardness $\left(H_{v}\right)$, brittleness index values $\left(\mathrm{H} / \mathrm{K}_{\mathrm{c}}\right)$, and calculated values of critical load $\left(\mathrm{P}_{\mathrm{c}}\right.$ - Eq. 14), and critical half diagonal length $\left(\mathrm{a}_{\mathrm{c}}\right.$ - Eq. 15) of AE-Si-O-N glasses. Meyer's hardness values $(\mathrm{H})$, like the instrumented indentation $\left(\mathrm{H}_{\mathrm{IT}}\right)$ values are comparatively higher than those of float glass and found to increase with increasing nitrogen content (see Fig. 6). If a material exhibits some cracking behaviour during indentation, we can extract the mechanical behaviour related to toughness, the indentation fracture toughness $\left(\mathrm{K}_{\mathrm{c}}\right)$. Eventhough the indentation toughness is more related to crack arrest due to residual stresses than crack propagation [32], the present data gives very useful partially quantitative information on the toughness of the high nitrogen content glass samples. The resistance to crack propagation $\left(\mathrm{K}_{\mathrm{c}}\right)$ tends to increase with increasing nitrogen content in both glass series (see Fig. 7). In the given series, $\mathrm{K}_{\mathrm{c}}$ values vary between 0.68 and 1.39 MPa.m ${ }^{1 / 2}$. Except for one glass composition, SG-2, the measured values are higher than far float glass. The Sr based glass series has lower toughness values than the Ca based glass series. $\mathrm{K}_{\mathrm{c}}$ values are found to increase with increasing glass compactness $\left(\mathrm{C}_{\mathrm{g}}\right)$ for both glass series. 
We can evaluate the residual stress field created by indentation loading from the expansion of an elasto-plastic expanding cavity and calculate the driving force for radial crack initiation based on Lawn and co-workers work. The brittleness index $\left(\mathrm{H} / \mathrm{K}_{\mathrm{c}}\right)$ reflects the interplay between plastic deformation and fracture [27]. For loads below Pc the indentation is hardness controlled while above $\mathrm{P}_{\mathrm{c}}$ it is toughness controlled [29]. The brittleness index shall be useful for ranking the susceptibility of materials to surface damage. In the given oxynitride series, brittleness values vary between 7.16 and $10.7 \mu \mathrm{m}^{-1 / 2}$ and the values of brittleness for the Ca based glasses are comparatively lower than the Sr based glasses and it is found that high nitrogen content glass results lower brittleness index values. In a way similar to the crack initiation observation, the $\mathrm{H} / \mathrm{K}_{\mathrm{c}}$ of the glass series was found to decrease with increasing $\mathrm{C}_{\mathrm{g}}$ or $v$ (see Fig. 8). The resistance to crack propagation $\left(\mathrm{K}_{\mathrm{c}}\right)$ of the high nitrogen glasses is almost twice that of the float glasses, and therefore, the brittleness values of the former are lower compared to the latter. The experimentally found critical load for cracking $\mathrm{P}_{\mathrm{c}}$, were not matching with the universal Eq. (14), (see Fig. 5) and the measured values are higher than the estimated values by a factor of 10 .

\section{Discussion}

For oxynitride glasses the compactness and molar volume are found to increase and decrease, respectively, with increasing nitrogen content [10]. A decrease of molar volume with increasing modifier cation field strength was shown by Ramesh et al. [22] Pastuzak et al. [21] verified that the density increases with increasing atomic number of AE for AE-Si-Al-O-N glasses with $\mathrm{AE}=\mathrm{Mg}, \mathrm{Ca}$ and $\mathrm{Ba}$. In accordance with these findings, the present $\mathrm{Sr}$ glasses have higher densities and molar volumes than the Ca glasses. The compactness increases with nitrogen content for both $\mathrm{Ca}$ and $\mathrm{Sr}$ glasses. Comparatively few studies have been carried out on $\mathrm{Ca}-\mathrm{Si}-\mathrm{O}-$ N [14] and Ca-Si-Al-O-N [2, 12, 16] glasses. Young's moduli for these, with N contents below 20 e/o, have been found to vary between 92 and $115 \mathrm{GPa}$. Hanada et al. [14] reported, notably higher values, up to $132 \mathrm{GPa}$, for Ca-Si-O-N glasses with $\mathrm{N}$ contents up to $35 \mathrm{e} / \mathrm{o}$.

A few studies have shown that oxynitride glasses exhibit high values of Poisson's ratio $[19,20]$. The present $\mathrm{Sr}$ series, $\mathrm{Sr}_{12.73} \mathrm{Si}_{10} \mathrm{O}_{20.08} \mathrm{~N}_{8.44}$ with 39 e/o of $\mathrm{N}$, shows high value of 0.308. In the Ca series, $\mathrm{Ca}_{12.90} \mathrm{Si}_{10} \mathrm{O}_{20.93} \mathrm{~N}_{7.98}$ glass, with 36.4 e/o of $\mathrm{N}$, shows a notably high $v$ value of 0.30. The data indicate furthermore that $v$ increases with increasing $\mathrm{N}$ content. It should be noted, 
however, that the Ca content increases roughly in proportion to the $\mathrm{N}$ content. Poisson's ratio is correlated to glass network connectivity. A highly cross-linked network leads to a small Poisson's ratio, whereas weakly correlated networks, exhibit values higher than 0.3 (up to 0.4) [18]. In agreement, a monotonic decrease of $v$ with $\mathrm{n}_{\mathrm{BO}}$ was observed (Fig. 3). Note that $\mathrm{n}_{\mathrm{BO}}$ does not vary monotonically with $\mathrm{N}$ e/o because of $\mathrm{n}_{\mathrm{BO}}$ dependence to AE e/o. Glass ID 1 (Table 1), with $\mathrm{N} 40.1$ e/o and Ca 33.2 e/o has a low Poisson's ratio because its $\mathrm{n}_{\mathrm{BO}}$ is very high in $\mathrm{Ca}$ series. Glass ID SG-2, with N 11.1 e/o and Sr 26.6 e/o has a low Poisson's ratio because its $\mathrm{n}_{\mathrm{BO}}$ is very high in Sr series. Nevertheless, AE-Si-O-N glasses show an expected trend of Poisson's ratios versus $\mathrm{n}_{\mathrm{BO}}$.

From the measured values of $\mathrm{H}_{\mathrm{IT}}$ and $\mathrm{E}_{\mathrm{r}}$ we can estimate the homogeneity of the sample from the surface to its bulk. Except for the high AE content, the narrow difference between the ultrasonic echography measured Young's modulus (E) and the instrumented elastic modulus ( $\left.\mathrm{E}_{\mathrm{IT}}\right)$ values shows that the sample has high homogeneity (Table 2 \& Fig. 1). Hardness values increases linearly with increasing nitrogen content in both $\mathrm{Ca}$ and $\mathrm{Sr}$ series (Fig. 6). All the samples show radial cracks under the $500 \mathrm{~g}$ load. Crack initiation studies with respect to the glass composition and elastic properties shows that when the atomic cross-linking degree decrease, the atomic packing increase and at the same time local shear becomes easier [34, 35].

Generally, the accepted view is that the substantial changes in physical properties of oxynitride glasses with increasing nitrogen content is due to an increased polymerization of the glass network by three-coordinated $\mathrm{N}$ atoms, $\mathrm{N}^{[3]}$. The $\mathrm{N}$ atoms in oxynitride glasses may be present, in different proportions, as $\mathrm{N}^{[3]}, \mathrm{N}^{[2]}$ and $\mathrm{N}^{[1]}$. Neutron powder diffraction studies on Na$\mathrm{Ca}-\mathrm{Si}-\mathrm{O}-\mathrm{N}$ and $\mathrm{Y}-\mathrm{Si}-\mathrm{Al}-\mathrm{O}-\mathrm{N}$ glasses indicate mixtures of 2- and 3-coordinated $\mathrm{N}$ [23], and an XPS study of Ca-Mg-Si-Al-O-N glasses indicates predominantly $\mathrm{N}^{[3]}$, but also the presence of $\mathrm{N}^{[2]}$ and $\mathrm{N}^{[1]}$ [24]. Indirect evidence for a significant fraction of $\mathrm{N}^{[3]}$ in oxynitride glasses lies in the observed increase in Young's modulus, $\mathrm{T}_{\mathrm{g}}$ and viscosity with increasing nitrogen content. This hypothesis is supported by the fact that the experimental values of Young's modulus, hardness and refractive index agree well with the calculation based physical properties of $\mathrm{Si}_{3} \mathrm{~N}_{4}$ crystal [33], suggesting thus that the $\mathrm{N}$ bonding is similar in oxynitride glasses and $\mathrm{Si}_{3} \mathrm{~N}_{4}$.

For many glassy systems it is found that Poisson's ratio decreases with increasing polymerization of glass network. The observed increase of $v$ with increasing $\mathrm{N}$ content in the present study would have suggested that nitrogen does not enhance the over all cross linking of 
the glass network. For the present glasses, the $\mathrm{X}: \mathrm{Si}, \mathrm{X}=(\mathrm{O}, \mathrm{N})$, ratio, $\mathrm{r}_{\mathrm{XT}}$, varies between 2.51 and 2.89. For pure oxide silicate glasses these values correspond to average network connectivity's of respectively layers of tetrahedra and rings or chains of tetrahedra. The $\mathrm{r}_{\mathrm{XT}}$ ratios thus seem to imply that the average network polymerization is low. The $r_{X T}$ ratio does furthermore not change systematically with nitrogen content. The elongated shapes of the determined glass forming regions for the M-Si-O-N glasses [3, 4], show that there is a strong correlation between the $\mathrm{N}$ content and the contents of the modifiers $\mathrm{M}$ and that the glasses have relatively constant $\mathbf{r}_{\mathrm{XT}}$ values.

The interpretation of the increase in elastic moduli, hardness, indentation toughness and Poisson's ratio, with increasing nitrogen content clearly calls for more structural investigation. In this case, the incorporation of $\mathrm{N}$ in a glass with constant $\mathrm{r}_{\mathrm{XT}}$ ratio can be expected to replace the equal amount of $\mathrm{O}^{[2]}$ by $\mathrm{N}^{[2]}$, accompanied by a corresponding increase of modifier $\mathrm{M}$ atoms. Possibly, bonding between the $\mathrm{N}^{[2]}$ atoms and the $\mathrm{M}$ atoms, due to the higher negative charge of $\mathrm{N}^{3-}$, could affect an increase in the stiffness of Si-X-Si linkages and thus an increase of the hardness of the glass.

\section{Summary}

We have studied elastic properties by means of ultrasonic echography and indentation behaviour for (Ca,Sr)-Si-O-N glasses, with $\mathrm{N}$ contents between 30 and 58 e/o. Young's modulus and shear modulus both increase linearly with $\mathrm{N}$ content, up to respectively 135 and $52.8 \mathrm{GPa}$ for the $\mathrm{Ca}$ series. Sr series glasses show lower moduli values than Ca glass series. Poisson's ratio tends to increase with increasing $\mathrm{N}$ content and is notably high, for the $\mathrm{Sr}$ glasses than the Ca glasses. Indentation results show that hardness values for both the glass series increase with increasing nitrogen content. Crack initiation load, indentation fracture toughness and also the surface damage resistance were found to increase with increasing nitrogen content.

\section{Acknowledgements}

Pathikumar Sellappan possesses fellowship from French ministry of Research. Saeid Esmaeilzadeh possesses a research fellowship from the Royal Swedish Academy of Sciences, financed by the Knut and Alice Wallenberg Foundation. The Swedish Research Council is 
acknowledged for financial support. The Brittany region, France is acknowledged for instrumental facilities (PENMAT proposal). 


\section{References}

1 S. Hampshire, R. Drew, K.H. Jack, Phys. Chem. Glasses., 26 (1985) 182-186.

2 S.Sakka, K. Kamiya, T. Yoko, J. Non-Cryst. Solids., 56 (1983) 147-152.

3 A. Sharafat, J. Grins, S. Esmaeilzadeh, J. Eur. Ceram. Soc., 28 (2008) 2659-2664.

4 A. Sharafat, J. Grins, S. Esmaeilzadeh, J. Mater. Sci., 44 (2009) 664-670.

5 A. S. Hakeem, J. Grins, S. Esmaeilzadeh, J. Eur. Ceram. Soc., 27 (2007) 4773-4781.

6 D. R. Messier, A. Broz, J. Am. Ceram. Soc., 65 (1982) C123-C123.

7 A. Sharafat, J. Grins, S. Esmaeilzadeh, J. Non-Cryst. Solids., 355 (2009) 301-304.

8 A. S. Hakeem, J. Grins, S. Esmaeilzadeh, J. Eur. Ceram. Soc., 27 (2007) 4783-4787.

9 H. Lemercier, T. Rouxel, D. Fargeot, J. L. Besson, B. Piriou, J. Non-Cryst. Solids., 201 (1996) 128-145.

10 M. J. Pomeroy, C. Mulcahy, S. Hampshire, J. Am. Ceram. Soc., 86 (2003) 458-464.

11 I. M. Peterson, T. Y. Tien, J. Am. Ceram. Soc., 78 (1995) 1977-1979.

12 D. N. Coon, J. G. Rapp, R. C. Bradt, C. G. Pantano, J. Non-Cryst. Solids., 56 (1983) 161166.

13 J. Homeny, D. L. Mcgarry, J. Am. Ceram. Soc., 67 (1984) C225-227.

14 T. Hanada, U. Naotaka, S. Naohire, J. Ceram. Soc. Jpn., 96 (1988) 281-289.

15 A. R. Hanifi, A. Genson, M. J. Pomeroy, S. Hampshire, J. Am. Ceram. Soc., 92 (2009) 1141-1144

16 C. Ecolivet, P. Verdier, Mater. Res. Bull., 19 (1984) 227-231.

17 R. D. Shannon, Acta. Crystallogr., A 32 (1976) 751-767.

18 T. Rouxel, J. Am. Ceram. Soc., 90 (2007) 3019-3039.

19 D. D. Graaf, Eindhoven University of Technology Ph.D thesis (2004).

20 T. Rouxel, N. Dély, J. C. Sangleboeuf, S. Dériano, M. LeFloch, B. Beuneu, S. Hampshire, J. Am. Ceram. Soc., 88 (2005) 889-896.

21 R. Pastuszak, P. Verdier, J. Non-Cryst. Solids., 56 (1983) 141-146.

22 R. Ramesh, E. Nestor, M. J. Pomeroy, S. Hampshire, J. Eur. Ceram. Soc., 17 (1997) 1933-1939.

23 S. Sakka, J. Non-Cryst. Solids., 181 (1995) 215-224.

24 M. Schneider, V. A. Gasparov, W. Richter, M. Deckwerth, C. Russel, J. Non-Cryst. Solids., 215 (1997) 201-207.

25 W. C. Oliver, G. M. Pharr, J. Mat. Res., 7 (1992) 1564-1582.

26 V.Keryvin, T. Rouxel, M. Huger, L. Charleux, J. Ceram. Soc. Jap., 116 (2008) 851-854.

27 G.R. Anstis, P. Chantikul, B. R. Lawn, D. B. Marshall, J. Am. Ceram. Soc., 64 (1981) 533-8

28 K. Niihara, R. Morena, D. P. H. Hasselman, J. Mater. Sci. Lett.,1 (1982) 13-6

29 V. Keryvin, V.H. Hoang, J. Shen, Intermetallics, 17 (2009) 211-217

30 D. B. Marshall, B. R. Lawn, P. Chantikul, J.Mater. Sci., 14 (1979) 2225-35.

31 B. R. Lawn, D. B. Marshall, J. Am. Ceram. Soc., 62 (1979) 347-50

32 G. D. Quinn, R. C. Bradt, J. Am. Ceram. Soc., 90 (2007) 673-80

33 C. Schrimpf, G. H. Frischat, J. Non-Cryst. Solids., 56 (1983) 153-159.

34 T. Rouxel, H. Ji, T. Hammoud, A. Moréac, Phys. Rev. Lett., 100 (2008) 225501-4.

35 H. Ji, V. Keryvin, T. Rouxel, T.Hammouda, Scr. Mater., 55 (2006) 1159. 


\section{Table 1}

Data for AE-Si-O-N (AE = Ca, Sr) glasses; determined glass composition, $\mathrm{N}$ content in e/o, Ca/Sr content in e/o, density $(\rho)$, molar volume (MV), compactness $\left(\mathrm{C}_{\mathrm{g}}\right)$, Young's modulus $(\mathrm{E})$, shear modulus $(\mathrm{G})$, bulk modulus $(\mathrm{K})$ and Poisson's ratio $(v)$.

\begin{tabular}{|c|c|c|c|c|c|c|c|c|c|c|c|}
\hline $\begin{array}{l}\text { Glass } \\
\text { ID }\end{array}$ & Glass composition & $\mathrm{N}(\mathrm{e} / \mathrm{o})$ & $\mathrm{AE}(\mathrm{e} / \mathrm{o})$ & $\rho\left(\mathrm{g} \cdot \mathrm{cm}^{-}{ }^{3}\right)$ & $\begin{array}{c}\mathrm{MV} \\
\left(\mathrm{cm}^{3} \cdot \mathrm{mol}^{-1}\right)\end{array}$ & $\mathrm{C}_{\mathrm{g}}$ & $\mathrm{n}_{\mathrm{BO}}$ & $\begin{array}{l}\text { Young's } \\
\text { modulus } \\
\text { E (GPa) }\end{array}$ & $\begin{array}{l}\text { Shear } \\
\text { modulus } \\
\mathrm{G}(\mathrm{GPa})\end{array}$ & $\begin{array}{c}\text { Bulk } \\
\text { modulus } \\
\mathrm{K}(\mathrm{GPa})\end{array}$ & $\begin{array}{c}\text { Poisson's } \\
\text { ratio } v\end{array}$ \\
\hline 1 & $\mathrm{Ca}_{9.94} \mathrm{Si}_{10} \mathrm{O}_{17.73} \mathrm{~N}_{8.14}$ & 40.1 & 33.2 & 3.02 & 7.76 & 0.575 & 3.34 & $\begin{array}{c}121.1 \pm \\
4.6\end{array}$ & $47.8 \pm 0.4$ & $86.6 \pm 1.0$ & $\begin{array}{c}0.267 \pm \\
0.014\end{array}$ \\
\hline 5 & $\mathrm{Ca}_{12.90} \mathrm{Si}_{10} \mathrm{O}_{20.93} \mathrm{~N}_{7.98}$ & 36.4 & 39.2 & 3.02 & 7.96 & 0.565 & 3.22 & $97^{*}$ & $37.3 *$ & $80.9 *$ & $0.30^{*}$ \\
\hline CG-3 & $\mathrm{Ca}_{12.26} \mathrm{Si}_{10} \mathrm{O}_{19} \mathrm{~N}_{8.84}$ & 42.0 & 38.0 & 3.03 & 7.91 & 0.570 & 3.25 & $114 \pm 3.2$ & $44.2 \pm 0.4$ & $91 \pm 1.0$ & $\begin{array}{c}0.291 \pm \\
0.011\end{array}$ \\
\hline 6 & $\mathrm{Ca}_{11.77} \mathrm{Si}_{10} \mathrm{O}_{16.30} \mathrm{~N}_{10.31}$ & 48.7 & 37.1 & 3.09 & 7.75 & 0.584 & 3.26 & $\begin{array}{c}118.5 \pm \\
3.4\end{array}$ & $46.1 \pm 0.4$ & $91 \pm 1.0$ & $\begin{array}{c}0.285 \pm \\
0.011\end{array}$ \\
\hline 7 & $\mathrm{Ca}_{11.04} \mathrm{Si}_{10} \mathrm{O}_{13.21} \mathrm{~N}_{11.89}$ & 58.0 & 35.6 & 3.24 & 7.37 & 0.618 & 3.29 & $135^{*}$ & $52.8^{*}$ & $102.3 *$ & $0.280^{*}$ \\
\hline SG-2 & $\mathrm{Sr}_{7.25} \mathrm{Si}_{10} \mathrm{O}_{24.20} \mathrm{~N}_{1.98}$ & 11.1 & 26.6 & 3.48 & 8.81 & 0.536 & 3.47 & $82.8 \pm 2.6$ & $32.8 \pm 0.3$ & $58.1 \pm 0.9$ & $\begin{array}{c}0.262 \pm \\
0.011\end{array}$ \\
\hline $\operatorname{Sr} 12$ & $\mathrm{Sr}_{9.50} \mathrm{Si}_{10} \mathrm{O}_{18.26} \mathrm{~N}_{7.49}$ & 38.1 & 32.2 & 3.90 & 8.56 & 0.573 & 3.36 & $\begin{array}{c}104.1 \pm \\
2.1\end{array}$ & $39.9 \pm 0.3$ & $89.1 \pm 1.0$ & $\begin{array}{c}0.305 \pm \\
0.011\end{array}$ \\
\hline SG & $\mathrm{Sr}_{12.73} \mathrm{Si}_{10} \mathrm{O}_{20.08} \mathrm{~N}_{8.44}$ & 39.0 & 39.0 & 4.09 & 8.76 & 0.571 & 3.23 & $\begin{array}{c}103.1 \pm \\
2.9\end{array}$ & $39.4 \pm 0.3$ & $89.6 \pm 1.0$ & $\begin{array}{c}0.308 \pm \\
0.011\end{array}$ \\
\hline
\end{tabular}

* - $v$ values were estimated using Fig 3. and E values were computed using Eq. (8), K values computed using Eq. (6) and $\mathrm{G}$ values computed using Eq. (16). 


\section{Table 2}

Instrumented indentation using Fischerscope H100C and Young's modulus values for AE-Si-O$\mathrm{N}(\mathrm{AE}=\mathrm{Ca}, \mathrm{Sr})$ glasses.

\begin{tabular}{|c|c|c|c|c|c|}
\hline \multirow[t]{4}{*}{ Glass ID } & \multicolumn{3}{|c|}{ Micro indentation } & \multirow{4}{*}{$\begin{array}{c}\text { E } \\
\text { (using USE } \\
\text { measurement) } \\
(\mathrm{GPa})\end{array}$} & \multirow{4}{*}{$\begin{array}{c}\mathrm{E}_{\mathrm{r}} \text { (using USE } \\
\text { measurement) } \\
(\mathrm{GPa}) \\
\text { Eq. (8) }\end{array}$} \\
\hline & $\mathrm{H}_{\mathrm{IT}}(\mathrm{GPa})$ & $\mathrm{E}_{\mathrm{r}}(\mathrm{GPa})$ & $\mathrm{E}_{\mathrm{IT}}(\mathrm{GPa})$ & & \\
\hline & under 100 & & Eq. (8) & & \\
\hline & $\mathrm{mN}$ load & & & & \\
\hline 1 & $12.4 \pm 0.3$ & $120.3 \pm 2.1$ & $111.7 \pm 1.9$ & $121.1 \pm 4.6$ & $130.4 \pm 4.6$ \\
\hline 5 & $10.7 \pm 0.3$ & $106.6 \pm 1.7$ & $97^{*}$ & - & - \\
\hline CG-3 & $9.7 \pm 0.5$ & $113.6 \pm 1.7$ & $103.9 \pm 1.6$ & $114 \pm 3.2$ & $124.6 \pm 3.2$ \\
\hline 6 & $9.2 \pm 0.7$ & $123.7 \pm 2.2$ & $113.6 \pm 1.9$ & $118.5 \pm 3.4$ & $129 \pm 3.4$ \\
\hline 7 & $12.7 \pm 0.3$ & $146.5 \pm 0.6$ & $135^{*}$ & - & - \\
\hline SG-2 & $8.1 \pm 0.1$ & $93.6 \pm 0.8$ & $87.2 \pm 0.8$ & $82.8 \pm 2.6$ & $88.9 \pm 2.6$ \\
\hline $\operatorname{Sr} 12$ & $8.4 \pm 0.2$ & $112.1 \pm 1.2$ & $101.68 \pm 1.1$ & $104.1 \pm 2.1$ & $114.8 \pm 2.1$ \\
\hline SG & $10.9 \pm 0.5$ & $112.1 \pm 1.7$ & $101.5 \pm 1.6$ & $103.1 \pm 2.9$ & $113.9 \pm 2.9$ \\
\hline WG & $6.5 \pm 0.2$ & $74.5 \pm 0.2$ & $70.7 \pm 0.2$ & $73.3 \pm 2.1$ & $77.17 \pm 2.1$ \\
\hline Silica & $8.96 \pm 0.4$ & $63.4 \pm 1.5$ & $62.1 \pm 1.4$ & $73.5 \pm 1.2$ & $75.1 \pm 1.2$ \\
\hline
\end{tabular}

* $-v$ values were estimated using Fig.3 and E values were computed using Eq. (8) 


\section{Table 3}

Meyer's hardness $(\mathrm{H})$, Vickers hardness $\left(\mathrm{H}_{\mathrm{v}}\right)$, indentation toughness $\left(\mathrm{K}_{\mathrm{c}}\right)$, brittleness values $\left(\mathrm{H} / \mathrm{K}_{\mathrm{c}}\right)$, critical load $\left(\mathrm{P}_{\mathrm{c}}\right)$ and critical half diagonal length $\left(\mathrm{a}_{\mathrm{c}}\right)$ for AE-Si-O-N $(\mathrm{AE}=\mathrm{Ca}, \mathrm{Sr})$ glasses.

\begin{tabular}{ccccccc}
\hline Glass ID & $\begin{array}{c}\mathrm{H}(\mathrm{GPa}) \\
\text { Under 500 } \\
\text { g load }\end{array}$ & $\begin{array}{c}\mathrm{H}_{\mathrm{v}}(\mathrm{GPa}) \\
\text { Under 500 } \\
\text { g load }\end{array}$ & $\begin{array}{c}\mathrm{K}_{\mathrm{C}}(\mathrm{MPa} \\
\left.\mathrm{m}^{1 / 2}\right) \\
\text { Eq. }(11) \\
\text { Under 500 } \\
\mathrm{g} \text { load }\end{array}$ & $\begin{array}{c}\mathrm{H} / \mathrm{K}_{\mathrm{C}} \\
\left(\mu \mathrm{m}^{-1 / 2}\right) \\
\text { Under 500 } \\
\text { load }\end{array}$ & $\mathrm{P}_{\mathrm{c}}(\mathrm{N})$ & $\mathrm{a}_{\mathrm{c}}(\mu \mathrm{m})$ \\
\hline 1 & $10.7 \pm 0.4$ & $9.9 \pm 0.4$ & $\begin{array}{c}1.02 \pm 0.13 \\
10.66 \pm 1.28\end{array}$ & 0.016 & 1.12 \\
5 & $8.6 \pm 0.2$ & $8.0 \pm 0.2$ & $1.01 \pm 0.09$ & $8.59 \pm 0.79$ & 0.027 & 1.67 \\
CG-3 & $9.9 \pm 0.2$ & $9.2 \pm 0.2$ & $1.18 \pm 0.05$ & $8.45 \pm 0.34$ & 0.032 & 1.70 \\
6 & $9.9 \pm 0.3$ & $9.2 \pm 0.2$ & $1.39 \pm 0.1$ & $7.16 \pm 0.51$ & 0.062 & 2.35 \\
7 & $10.8 \pm 0.5$ & $10.0 \pm 0.5$ & $1.37 \pm 0.12$ & $7.96 \pm 0.76$ & 0.047 & 1.97 \\
SG-2 & $6.8 \pm 0.2$ & $6.3 \pm 0.2$ & $0.68 \pm 0.06$ & $10.13 \pm 0.96$ & 0.011 & 1.20 \\
Sr12 & $8.9 \pm 0.3$ & $8.3 \pm 0.3$ & $0.95 \pm 0.11$ & $9.47 \pm 1.18$ & 0.021 & 1.42 \\
SG & $8.5 \pm 0.2$ & $7.9 \pm 0.2$ & $1.03 \pm 0.09$ & $8.35 \pm 0.69$ & 0.030 & 1.76 \\
WG & $6.67 \pm 0.4$ & $6.2 \pm 0.4$ & $0.79 \pm 0.03$ & $8.43 \pm 0.28$ & 0.022 & 1.72 \\
Silica & $10.0 \pm 0.4$ & $9.3 \pm 0.4$ & $*$ & $*$ & $*$ & $*$
\end{tabular}

* - there were no radial cracks observed to calculate the values 


\section{FIGURE CAPTIONS}

Figure 1. Young's modulus (E) as a function of nitrogen content for $A E-S i-O-N(A E=C a, S r)$ glasses. * $-v$ values were estimated using Fig 3. and E values were computed using Eq. (8). The dotted lines are guide for the eyes.

Figure 2. Shear modulus $(G)$ as a function of nitrogen content for $A E-S i-O-N(A E=C a, S r)$ glasses. * $-v$ values were estimated using Fig. 3 and E values were computed using Eq. (8) and G values calculated using Eq. (16). The dotted lines are guide for the eyes.

Figure 3. Poisson's ratio as a function of the number of bridging oxygen atoms per glass-forming cation, $n_{B O}$, for AE-Si-O-N $\left(A E=C a\right.$, Sr) glasses. * $-v$ values were estimated based on the $n_{B O}$ values from Table.1. The dotted lines are guide for the eyes.

Figure 4. Glass compactness $\left(C_{g}\right)$ as a function of Bulk modulus $(K)$ for $A E-S i-O-N(A E=C a, S r)$ glasses. ${ }^{*}-v$ values were estimated using Fig. 3 and $E$ values were computed using Eq. (8) and $K$ values calculated using Eq. (6). The dotted lines are guide for the eyes.

Figure 5. Experimentally measured and calculated critical load for cracking $P_{c}$ as a function of Poisson's ratio for AE-Si-O-N (AE = Ca, Sr) glasses. Please refer the text for more explanation.

Figure 6. Meyer's hardness (under $500 \mathrm{~g})$ as a function of nitrogen content for $A E-S i-O-N(A E=$ $\mathrm{Ca}, \mathrm{Sr})$ glasses. The dotted lines are guide for the eyes.

Figure 7. Indentation toughness $K_{c}$ (under $500 \mathrm{~g}$ - using Eq. (12)) as a function of nitrogen content for AE-Si-O-N (AE = Ca, Sr) glasses. The dotted lines are guide for the eyes.

Figure 8. Indentation brittleness index $\mathrm{H} / \mathrm{K}_{c}$ (under $500 \mathrm{~g}$ ) as a function of Poisson's ratio for AE-Si-O-N $(A E=C a, S r)$ glasses. The dotted lines are guide for the eyes. 


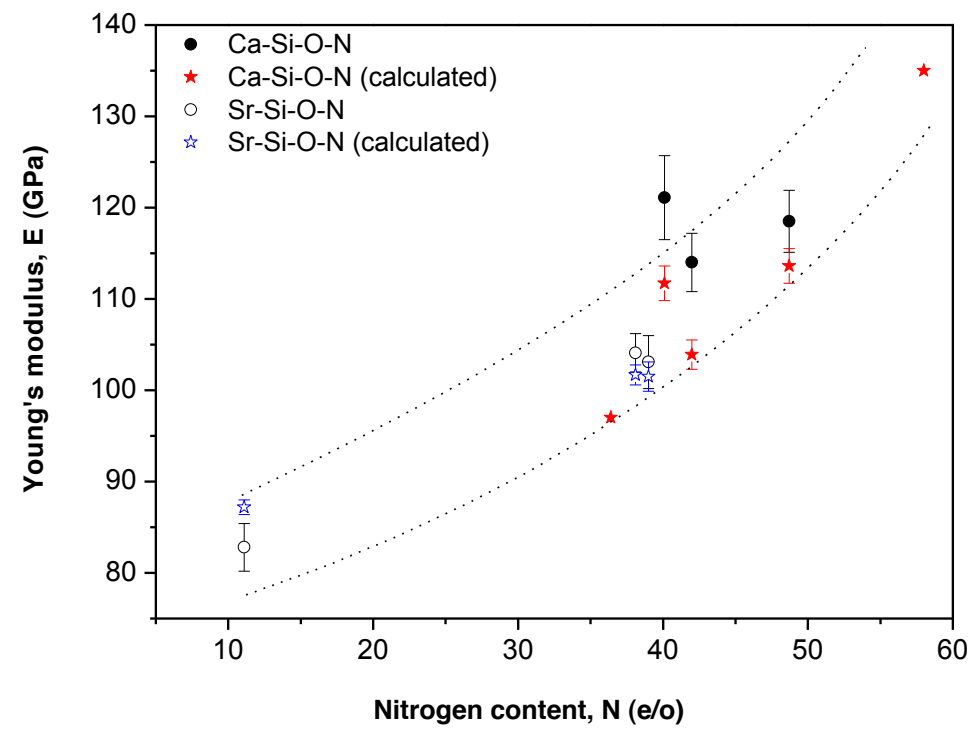

Figure 1. Young's modulus (E) as a function of nitrogen content for AE-Si-O-N (AE $=\mathrm{Ca}, \mathrm{Sr}$ ) glasses. * $-v$ values were estimated using Fig. 3 and E values were computed using Eq. (8). The dotted lines are guide for the eyes. 


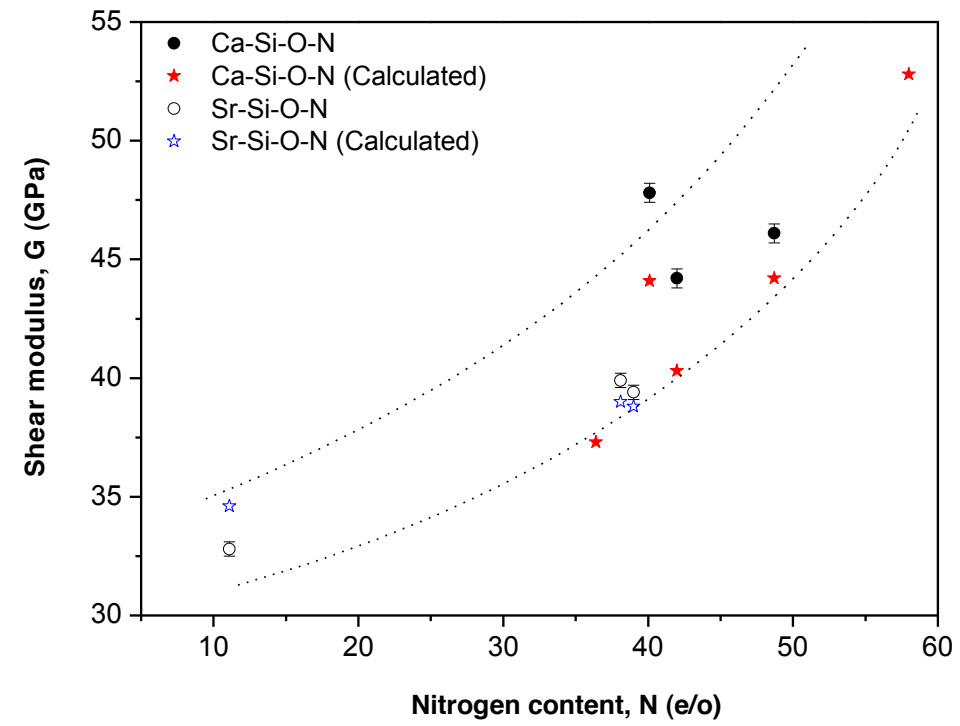

Figure 2. Shear modulus $(\mathrm{G})$ as a function of nitrogen content for AE-Si-O-N (AE $=\mathrm{Ca}, \mathrm{Sr}$ ) glasses. * $-v$ values were estimated using Fig. 3 and E values were computed using Eq. (8) and G values calculated using Eq. (16). The dotted lines are guide for the eyes. 


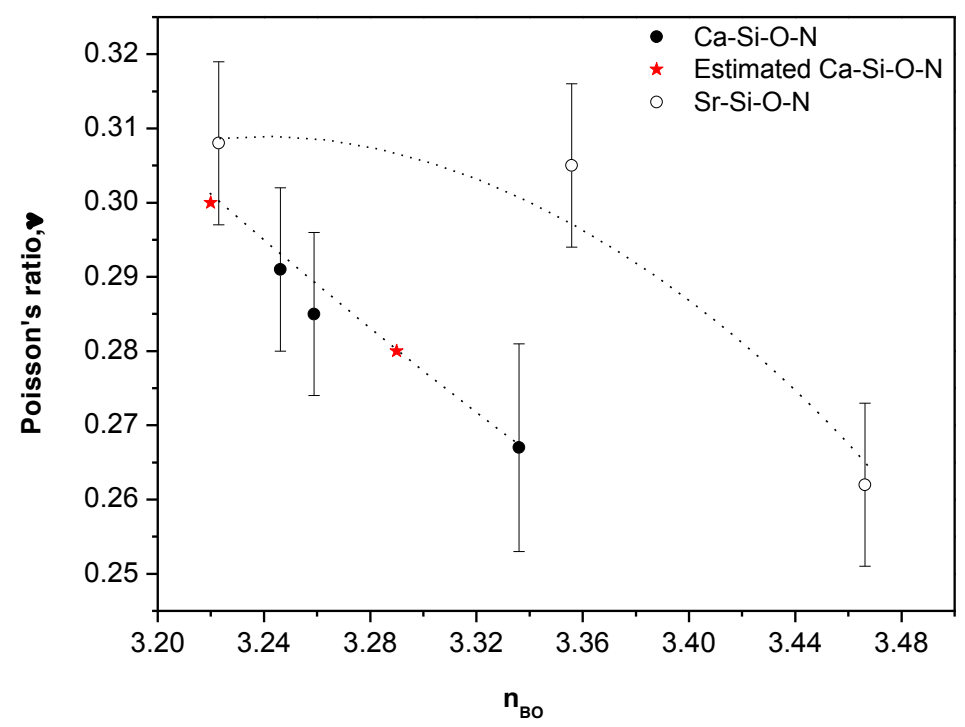

Figure 3. Poisson's ratio as a function of the number of bridging oxygen atoms per glass-forming cation, $\mathrm{n}_{\mathrm{BO}}$, for AE-Si-O-N (AE $\left.=\mathrm{Ca}, \mathrm{Sr}\right)$ glasses. ${ }^{*}-v$ values were estimated based on the $\mathrm{n}_{\mathrm{BO}}$ values from Table 1 . The dotted lines are guide for the eyes.

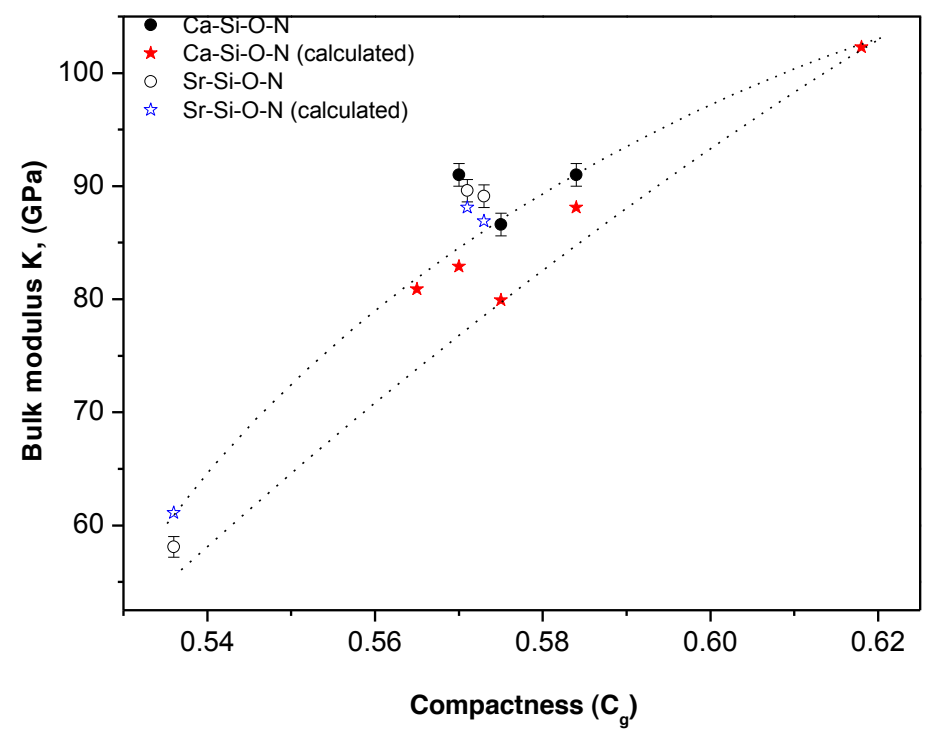

Figure 4. Glass compactness $\left(\mathrm{C}_{\mathrm{g}}\right)$ as a function of Bulk modulus $(\mathrm{K})$ for AE-Si-O-N (AE $=\mathrm{Ca}$, Sr) glasses. * $-v$ values were estimated using Fig. 3 and E values were computed using Eq. (8) and $\mathrm{K}$ values calculated using Eq. (6). The dotted lines are guide for the eyes. 


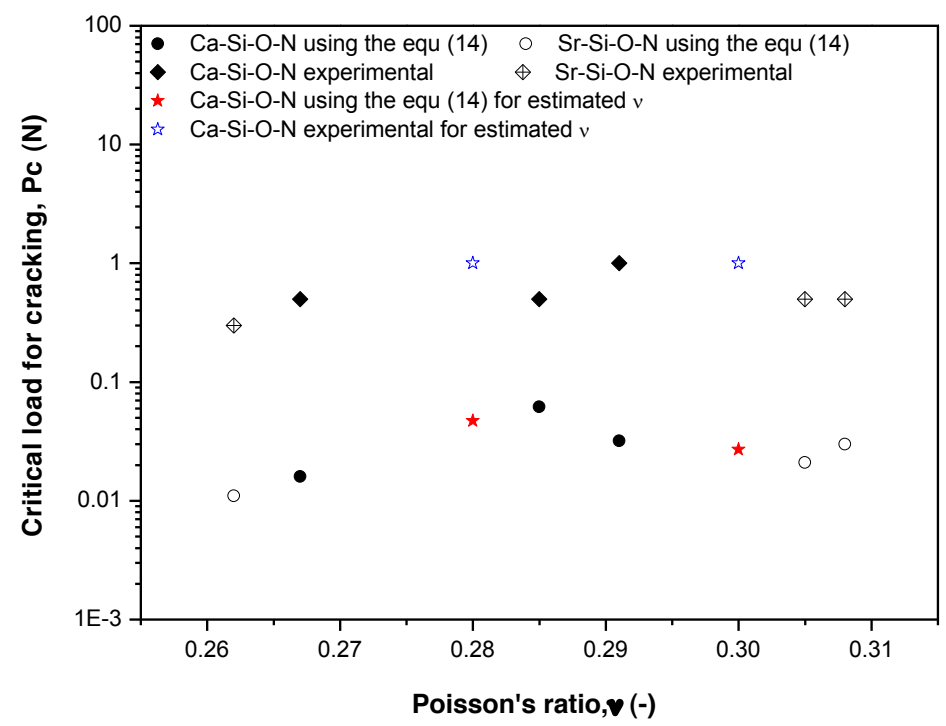

Figure 5. Experimentally measured and calculated (using $\lambda_{0}=16000$ ) critical load for cracking $\mathrm{P}_{\mathrm{c}}$ as a function of Poisson's ratio for AE-Si-O-N ( $\mathrm{AE}=\mathrm{Ca}, \mathrm{Sr})$ glasses. Please refer the text for more explanation.

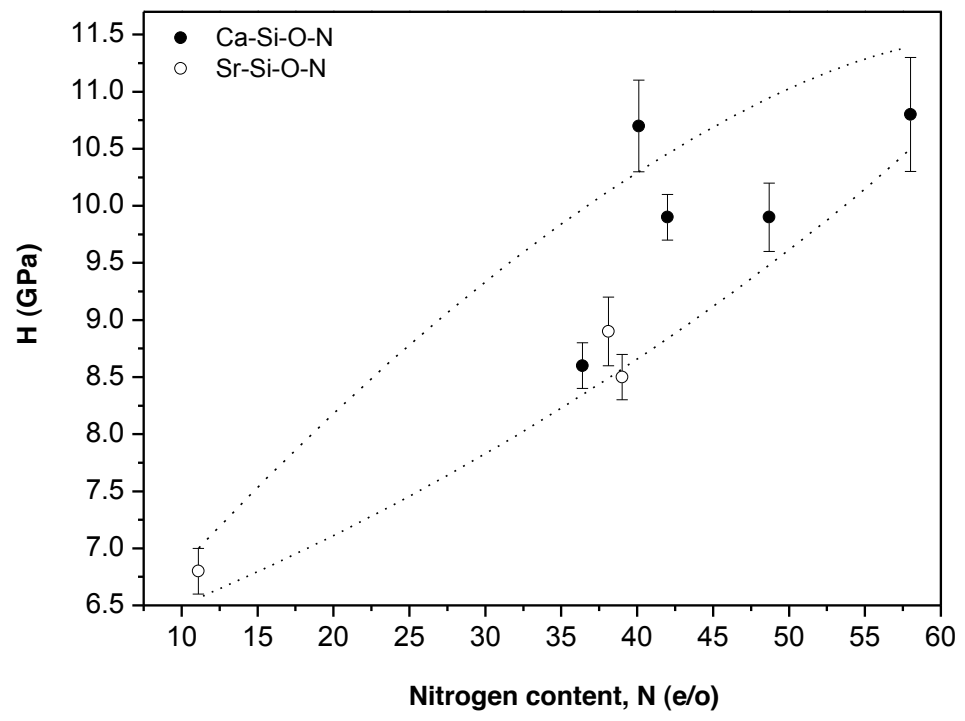

Figure 6. Meyer's hardness (under $500 \mathrm{~g}$ ) as a function of nitrogen content for AE-Si-O-N (AE = $\mathrm{Ca}, \mathrm{Sr})$ glasses. The dotted lines are guide for the eyes. 


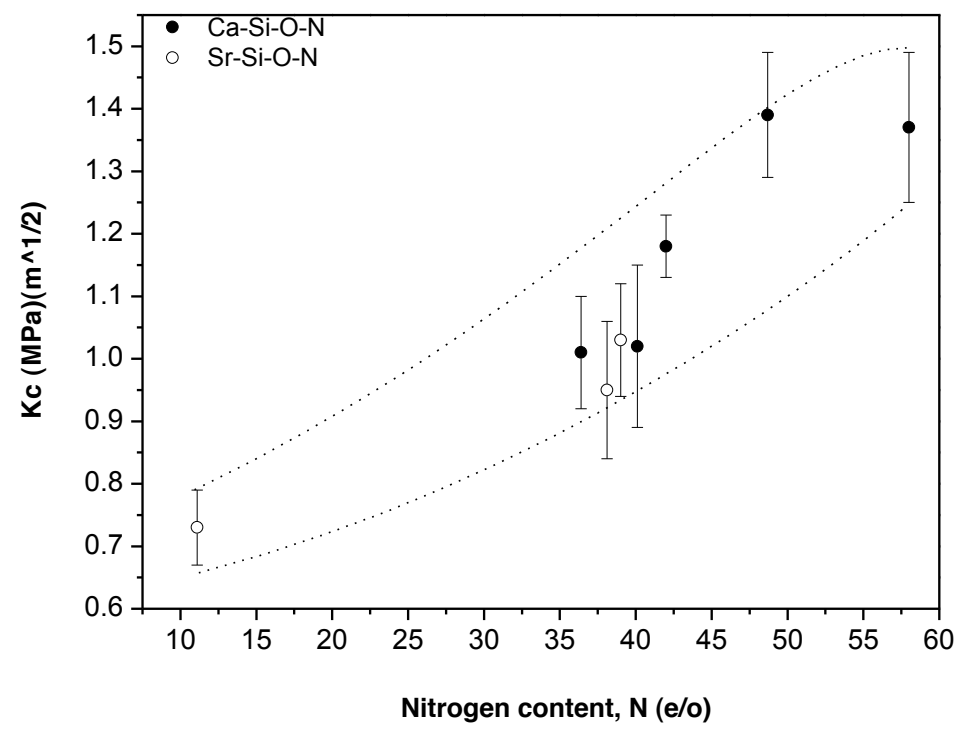

Figure 7. Indentation toughness $\mathrm{K}_{\mathrm{c}}$ (under $500 \mathrm{~g}$ - using Eq. (12)) as a function of nitrogen content for AE-Si-O-N ( $\mathrm{AE}=\mathrm{Ca}, \mathrm{Sr})$ glasses. The dotted lines are guide for the eyes.

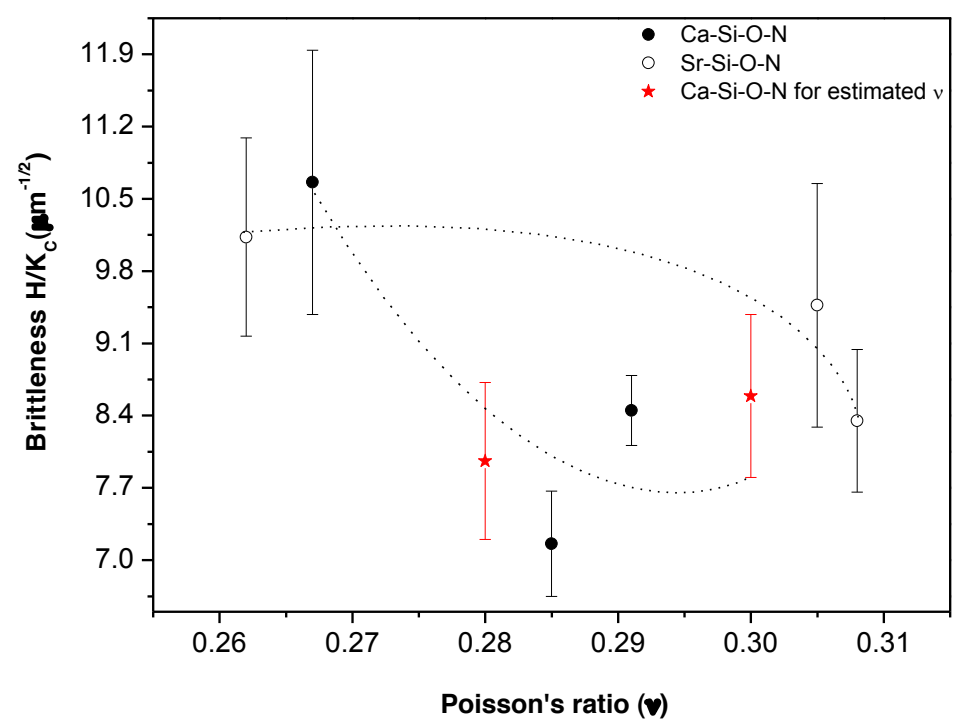

Figure 8. Indentation brittleness index $\mathrm{H} / \mathrm{K}_{\mathrm{c}}$ (under $500 \mathrm{~g}$ ) as a function of Poisson's ratio for AE$\mathrm{Si}-\mathrm{O}-\mathrm{N}(\mathrm{AE}=\mathrm{Ca}, \mathrm{Sr})$ glasses. The dotted lines are guide for the eyes. 